\title{
Scientific collaboration in South Africa
}

AUTHOR:

Radhamany Sooryamoorthy

\section{AFFILIATION:}

Sociology Programme, School of Social Sciences, University of KwaZulu-Natal, Durban, South Africa

\section{CORRESPONDENCE TO:}

Radhamany Sooryamoorthy

EMAIL:

sooryamoorthyr@ukzn.ac.za

POSTAL ADDRESS:

School of Social Sciences,

University of KwaZulu-Natal,

Howard College Campus,

Durban 4041, South Africa

\section{KEYWORDS:}

scientific collaboration;

collaboration model; science;

South Africa; Africa

\section{HOW TO CITE:}

Sooryamoorthy R. Scientific collaboration in South Africa. S Afr J Sci. 2013;109(5/6), Art. \#a0016, 5 pages. http://dx.doi org/10.1590/sajs.2013/a0016

\section{(c) 2013. The Authors.}

Published under a Creative

Commons Attribution Licence.
Science is a priority for most countries. But for a host of reasons science is on the decline on the African continent, the Cradle of Humankind. This crisis has been brewing since the 1990s, after an active institutional development in the 1970s and 1980s. ${ }^{1}$ The reasons for this decline range from a lack of resources (human and machine) to deprived working environments. Besides these reasons, diminishing resources in general, and for science in particular, tyrannical rule in many countries, deterioration of teaching and research, and the demoralisation of scientists have contributed to the situation, and not in a small measure. ${ }^{2}$ As the former Deputy Director General of UNESCO aptly said, 'Political independence without scientific knowledge and competence is as contradictory as the concept of a vegetarian tiger' (cited in Odhiambo ${ }^{3}$ ).

Science in Africa is now centred in the northern and southern extremities of the continent. ${ }^{1}$ There is a clear division in scientific productivity between the northern African states and the sub-Saharan states. Egypt, Algeria, Mauritania, Libya, Morocco and Tunisia are prominent among the northern African countries for their growing scientific outputs.

The location of a nation on the map of scientific research is determined not solely by its scientific activity, but also by factors that contribute to that very activity. Studies have examined and found the conditions that control the production of scientific knowledge. Research undertaken by a nation is strongly influenced by its wealth which is a prerequisite for scientific growth. ${ }^{4}$ Gross national product and its proportion spent on R\&D are some straightforward indicators of scientific activity. But there are others, and not all are obvious. Intrinsically, scientific activity is an interaction between scientists and their socio-technological environment. Processes such as collaboration are part of this interaction, having consequences for the production of knowledge and the scientific wealth of nations. Collaboration, domestic or international, accelerates scientific growth and advancement.

Science is no longer a centralised activity located in a single place, but is dispersed far and wide. Hicks and $\mathrm{Katz}^{5}$ rightly predicted that, in future, items of knowledge will be produced by more people in more locations. Scientific research is increasingly carried out collaboratively in teams of individuals, institutions and countries. Collaboration enhances the competency, skills and knowledge of partners while ensuring the quality of research. It strengthens scientific activities and capabilities; and failure in collaboration weakens science and technical enterprise. ${ }^{6}$ The substantial fall in the costs of air travel and communication, and advances in effective information and communication methodologies accelerate collaborative activities. ${ }^{7}$ In collaborative enterprises, the location of partners is shifting and is becoming more dispersed. ${ }^{8}$ Distance is no longer a matter of serious concern in collaboration, although progress in information and communication technologies (ICTs) has not taken place uniformly across the world.

International consortia of sciences are forming. ${ }^{5}$ Japan, after World War II, put in place a number of systems to promote collaborative research and development amongst researchers in universities, industries and government laboratories. ${ }^{9}$ Established nationwide, Research Associations is one such structure that has wider acceptance in Japanese society. ${ }^{9}$ The International Scientific Unions in the USA are the backbone of international scientific collaboration. ${ }^{10}$ The USA has developed an institutional mechanism to conduct regular monthly meetings to discuss the opportunities for new collaborations, review and assess the existing collaborations, and recommend future collaborations. ${ }^{11}$ The European Research Area within the European Union is another configuration for scientific and technological cooperation. ${ }^{12}$

The production of scientific knowledge is no longer the monopoly of universities. Equally important are non-academic institutions, engaged in groundbreaking research. Closer university-industry alliance is backed by both parties for mutually beneficial research outcomes. Industries profit from the intellectual pool of academics in universities for inventions that lead to new industrial products and applications. In return, universities secure funding and equipment.

\section{What is scientific collaboration?}

New forms of collaboration are emerging, characterised by complexity in the division of work, an interdisciplinary approach, adoption of procedures, formation of assisting structures and utilisation of communication technologies. Modern forms of collaboration entail greater dependence on external authorities and structures, and greater centralisation of authority in research organisations. ${ }^{13}$ Collaboration, in essence, is between individuals and not institutions. ${ }^{7}$ Individual scientists are the real actors in research alliances, while institutions play a secondary role. In institution-initiated alliances too, individual scientists are the key actors while the institution provides the support required to realise an alliance.

Collaboration is a working relationship involving equipment and laboratories, as well as human beings. Often individual scientists are the initiators, banking on informal contacts and acquaintances. However, when alliances stem from informal contacts, responsibilities are unclear; and when commitment is uncertain, collaboration can become stressful. ${ }^{14}$ Because not much is known about the cultural and attitudinal dimension of academic behaviour, ${ }^{15}$ understanding the personal components in collaboration is not always easy. But knowledge about the cultural and attitudinal dimensions of academic activity can shed light on the human side of collaboration.

To benefit fully from collaboration, the parties (individuals, institutions or countries) need to reach a certain level of scientific absorptive capacity, including the infrastructure of support, communication and research (Wagner et al. 2001 cited in Olson et al. ${ }^{16}$ ). They need to have a fair idea about the costs and benefits. ${ }^{17}$ Meticulous cost-benefit analysis works in multiple ways. It lends the partners the opportunity to assess the worth of their involvement, 
and maintains their interest and commitment throughout the duration of the project. Costs and benefits vary according to the size - the number of institutions or scientists - of the collaboration. Costs are incurred in terms of administration, coordination, travel, communication, occasional face-to-face meetings, and the real work of the partners. Amongst the benefits are access to equipment, knowledge, skills, expertise, interaction, publication and citation.

Collaboration has structural and personal elements. If personal components are not aligned properly with the structural ones, collaborations fall away. The balance between these complementary elements contributes to the maintenance of collaborative efforts. Structural reasons are to gain access to the infrastructure and the skills required in a research project while the personal ones are the individual reasons to (or not to) collaborate with someone who might be a friend, companion, long-standing associate or professional contact. Intellectual companionship and freedom from academic isolation motivate scientists to seek productive, fulfilling research alliances. Personal, face-to-face and informal contacts can spur people to associate on a research project. It is the intrinsic social nature that makes collaboration a personal choice, be it whether to collaborate or not, when and where, and for how long. Focused scientific purpose or a joint experiment which has the potential for a new discovery might not serve to bind the partners for the entire span of collaboration if the idiosyncrasies of the participating scientists are not taken into account. Collaborators leave midway for personal reasons. As it is a socio-cognitive process, the success of the researcher in collaboration depends on their success both as social individuals and as scientists. ${ }^{18}$

Reiterated in the literature is the importance of prior relations, working or personal, in successful alliances. Partners - individuals and institutions - who knew each other or maintained contacts strike an accord in collaborations. This prior connection gives a feeling of solidarity in partnerships, underlining the target of collective goals. The choice of a partner, if not the country or institution, is invariably a personal decision, taking into account the constituent components such as informal relationships, acquaintance, previous knowledge, prior working experience and trust. Research partnerships have spontaneous origins as well, such as informal conversations in scientific meetings or conferences.

Managing collaboration, irrespective of size, requires careful planning, coordination and administration. ${ }^{19}$ Collaboration, as Bozeman and Corley $^{20}$ put it, is much more than just getting the work out the door. It creates a sense of responsibility and commitment amongst the partners. ${ }^{14}$ In large-scale collaborations more formal organisational and managerial structures are required. ${ }^{11}$ Corresponding institutional changes ${ }^{17}$ are made, and the required structures and mechanisms need to be in place to avoid administrative and technical hitches. The administrative component is critical for success. When the responsibility of administration and management of the project falls on the shoulders of the senior scientist/s or the originator it can be burdensome. ${ }^{19}$ Distributing these tasks among partners, thereby minimising the load on a particular partner, is one way to reduce the burden.

Collaborative efforts become effective if there is agreement on division of labour, shared decision-making and collective responsibility. Maintenance of leadership and participation of partners in a team are critical. ${ }^{21}$ Leadership in collaboration can be neither authoritarian nor similar to normal institutional practice. Leadership has to be characterised by equality and understanding. ${ }^{21}$ As a respondent of Hagstrom ${ }^{13}$ remarked, '[t]here you have a strong norm. Telling someone what to do is a taboo. The greatest man in science cannot tell the lowest what to do.' The notion of equality comes into play at different stages. ${ }^{22}$ Mutual respect and recognition, irrespective of skills, knowledge or location, regular communication on project matters without regard for seniority, and more or less equally distributed benefits are contributing conditions in collaboration. The relationship between partners is symbiotic, characterised by dissimilarity, pursuit of mutual self-interests, and attainment of self-interest. ${ }^{22} \mathrm{~A}$ sound collaboration relies on a 'give and take' attitude. No individual's point of view dominates and the authority for decisions and actions resides with the group, and not with one or two partners (Minnis et al. 1994 cited in John-Steiner et al. ${ }^{23}$ ).

Lack of transparency in regard to objectives, process, the allocation of work, benefits, obligations, coordination and funds can cause ruptures in scientific alliances. Partners might not consider this a serious matter as long as there is an intermittent flow of funds and the work is carried out on a predetermined schedule. Agreed conditions in the form of a formal contract might allay many anxieties regarding transparency.

Collaboration is to be balanced, not skewed in favour of one party. The popular perception is that in such alliances the developing countries realise a larger return in equipment, materials and training. ${ }^{24}$ That collaboration is a way to get access to the developed scientific knowledge and their technology ${ }^{25}$ is a deliberately propagated view. This view might be true in cases where purely technological collaborations take place, but it invariably is not the case in scientific collaborations. In part, this view takes its origin from the divide between the developed and the developing, and that the latter always need the support of the former. Neglected in this discourse is the value and worth of the scientific data and knowledge that the developed countries acquire from the developing countries through such alliances. Quite evident from successful instances of collaboration is the balance in the collaboration configuration as we find when Africans provide access to local communities and the non-Africans provide needed equipment and training. ${ }^{26}$ Collaborative activities function and proceed well when the partners recognise the reality that the source of funds is equivalent to the source of resources; none is superior to the other. It is true that for scientists in many developing countries (except for a few prestigious institutions within them), in contrast to those in developed countries, that the cost of collaboration is at a premium. Basic essentials for conducting research, namely, phone calls, postage, the Internet, email, stationery, printing and copying, library searches, databases, assistance and local travel - not to mention equipment and laboratory material - are not always at the disposal of the scientists in poorer countries. These are structural hurdles in materialising alliances, at least in the conceiving phase before funds are actually released.

Transparency is vital in collaboration. Hame ${ }^{27}$ noted some inherent, ex ante determinants of transparency: penetrability of the social context that surrounds the partner, attitudes towards outsiders, the extent to which the partner's distinctive skills are discrete and the partner's pace of skill-building. Transparency is important in sharing the data produced in alliances. The ownership of data in scientific collaboration deserves due consideration before it becomes a matter of conflict and legal battle.

The challenges of collaboration are inherent and imminent. If handled properly and timeously they can make collaboration stronger. ${ }^{28}$ If not, they can drift into serious trouble that shakes the foundation of the collaboration. Walsh and Maloney ${ }^{29}$ remind us that size, geographic distance, interdependency and competitiveness can exacerbate the challenges. But these can be overcome with the appropriate use of communication technologies that bring the partners closer than ever before.

To deal with conflicts, general rules and principles should be laid down. ${ }^{30}$ Informal collaborations, involving a group of a few intimate colleagues, might not require rules to succeed. Formal rules for such a close team of partners are a constraint rather than a precondition. Given the nature of human relations, partners cannot be assured of the same set of relationships throughout the entire period of collaboration. Agreed rules, principles and codes of conduct are useful on occasions when personal intimacy of relationships is transformed into professional relationships. In the light of experience, some have argued for guidelines that can be used as a reference point in these circumstances. ${ }^{31}$ What is advisable, as suggested by Bozeman and Boardman ${ }^{11}$, is the adoption of a framework for collaboration if it has worked well previously, but definitely with amendments. This proposition is helpful to draw up the structures and norms for a new collaboration venture. Universal application of the framework is, however, doubtful when the partners, discipline, field, topic, objectives and methodologies differ. 
Some institutions work within the rules they have drawn up. These rules might identify their focus areas, preferred partner countries, sectors, institutions and laboratories, immediacy of problems that need to be researched, costs and benefits. For instance, institutions might have a rule for the interdisciplinary nature of collaboration; or a rule that a collaboration should form within the framework of the existing institutions rather than seeking to develop new institutions; or another one regarding the sectoral composition of collaborations. ${ }^{11}$ These rules are often based on previous experiences or stem from the assessment of the resources, preferences and needs of individual institutions.

Collaboration, for its initiation, execution and successful conclusion, requires a great many prerequisites. In the African context, as Keay ${ }^{32}$ recommends, governments should be willing to recognise scientific merit for the benefit of their countries without political considerations.

\section{Scientific collaboration in South Africa}

South Africa has long recognised the indispensability of science for progress. Collaboration has been considered as part and parcel of science, which is now promoted with vigour. Over the years the scientific capabilities of South Africa have grown impressively, placing us on a par with partners in collaborative ventures. Having a proven ability to produce world class science, the opportunities for collaboration are expanding in South Africa. ${ }^{33}$ More and more, the need for collaboration is seen at various levels, not just from scientists alone. One other reason for collaboration is the shortage South Africa is facing in its skilled personnel of technologists, artisans, managerial professionals and engineers.

South Africa has a leading role in collaboration with other African countries. The country is seeking ways and means to enhance its R\&D performance, which has been acknowledged as a key component in its economic strategic growth. ${ }^{34}$ The proposed target of the national R\&D strategy is in tandem with this. By 2012, the national R\&D strategy aims at increasing: research and technology enablers (matriculants with university exemptions in mathematics and science) from the current level of $3.4 \%$ to $7.5 \%$, the proportion of science, engineering and technology tertiary students from $20 \%$ to $30 \%$, the number of science, engineering and technology practitioners from 7 to 11 per 10000 workforce, the number of South African originated US patents from 100 to about 200, and government R\&D expenditure to GDP from $0.36 \%$ to $0.66 \% .{ }^{35}$

Explicit in the R\&D strategy document, ${ }^{35}$ South Africa recognises that science is global (with a share of $0.5 \%$ of the global science) and its scientists have to be well connected with the world body, not only by developing collaborations across the African continent but also by tapping into international resources. At the same time, more resources and time have to be invested in basic research which in 2001-2002 was about $27 \%$ of the total R\&D.

Revitalising the regional and national research institutes and finetuning higher education institutions in South Africa will boost scientific cooperation. Scientific cooperation will also help the country to take advantage of its reserve of rare natural resources and data mines that are essential for crucial scientific discoveries in which many developed countries are interested. A set of policies, coupled with fitting structures, can give support to collaborative initiatives. Some policy initiatives are already in place. Quite clear in a number of policy documents is the emphasis on collaborative efforts within and outside the country. ${ }^{35,36}$ The Innovation Fund of the Department of Science and Technology has the objective of advancing transdisciplinary collaboration across sectors in South Africa. ${ }^{37}$ Centres of Excellence, research teams, research centres and work groups are formed to facilitate and support collaborative efforts between disciplines, universities, industries, other institutions, regions and countries. As argued in a well-thought-out policy document, ${ }^{38}$ South Africa has to open its doors to a strong and steady inflow of ideas and scientists. Also heard is the call for policies and programmes to promote unimpeded movement of scientific and technical information to the national and international systems and to encourage South African scientists to participate in national, regional and international collaborative ventures. ${ }^{36,39}$ Being a regional and a continental power in matters of scientific research, South Africa stands to benefit from prospective alliances. The existing networks with SADC (Southern African Development Community) and NEPAD (New Partnership for African Development) have turned out to be unsustainable for want of resources, ${ }^{35}$ preventing effective collaboration with member countries.

More investment in R\&D, international collaboration, development of skilled persons and further opening up of the South African knowledge economy are necessary. ${ }^{34}$ The aging and shrinking scientific population is skewed by gender and race. ${ }^{36,40}$ As seen in the share of the output of researchers who have crossed the age of $50,{ }^{35}$ the scientific system warrants immediate redress, preventing the decline of the country's scientific potential. ${ }^{36}$

South Africa has strengths in astronomy, ecology, environmental science, natural sciences and plant and animal sciences. As rightly identified in the national R\&D strategy, ${ }^{35}$ South Africa holds key areas that are geographically and technically advantageous. Access to clear southern skies and the technology to build telescopes, excellent sites for further excavations in human palaeontology, the presence of the Cape Floral Kingdom (one of the seven most diverse floral kingdoms in the world), the only African country with a presence on the Antarctic continent, avant-garde mining technologies, the strides achieved in microsatellite engineering, the successful feats in encryption technology, competence in fluorine technology in the uranium enrichment programme, and developments in HIV/AIDS research, work in favour of South Africa, nationally and internationally, inviting prospective collaborators and partners.

A recent conference under the auspices of the Department of Science and Technology in association with the Africa Institute and the Human Sciences Research Council, which brought together government officials, higher education managers, managers of the science councils, representatives from the private sector and civil society along with researchers and experts has formulated a plan of action. This document, amongst others, strongly advocates the recruitment and retention of high-level scientific and technological personnel in the country; promotion of partnerships between universities, research councils and the industry; engagement with scientific globalisation such that South Africa can become a hub of research activities in appropriate areas to attract talented researchers; and promotion of institutional collaborations within and across national boundaries. ${ }^{36}$

\section{The South African model}

The model of scientific collaboration in South Africa that has emerged from a series of studies conducted in the last few years ${ }^{41-50}$ is unique in several respects and can perhaps offer some lessons for other countries. In South Africa, scientific collaboration is an accepted practice among scientists, supported by the government, higher education institutions, research institutes, industry, the private sector and individual scientists. Collaboration is considered part of the scientific enterprise. ${ }^{45}$ The structural support for collaboration is seen in the positive policy decisions taken at governmental level and implemented in the centres of research and academic activity. The reward system that is in place for the promotion of publication productivity encourages scientists to form alliances with international partners. ${ }^{45}$

Historically, the flow of scientists in and out of the country, the exchange of scientific personnel and collaborative scientific activities, occurred unhindered. ${ }^{45}$ This practice began from the later part of the 17 th century when South Africa became a colony, first under the Dutch and then under the British. The colonial government(s) lured scientists and academics to the land and supported their scientific pursuits. ${ }^{45}$ Many of these scientists became instrumental in building scientific disciplines across the country, providing able leadership and direction to scientific research in government departments, universities and research institutes. Our colonial legacy and a focus on specific branches of science, and their consequent growth in South Africa, are distinctive, if not unparalleled, in the history of science. Professional associations, representing various branches of science, are proactive in their efforts towards scientific growth and collaboration. Collaboration continued even during the apartheid era when, because of its racial segregation policies, the country was subject to isolation and boycotts by the international community. ${ }^{45}$ 
Collaboration grew into an accepted and recognised practice and norm, which was not the case with other African or Asian countries.

Distance does not matter in collaboration. South Africans partner with scientists from countries all over the world, notably with those in distant locations. ${ }^{43,48}$ Like geographical limits, disciplinary boundaries are not restrictions for South African scientists. Some branches of science such as medicine, and plant and animal sciences are more collaborative and productive than other branches. Collaboration during apartheid abetted the country to keep its advantageous position in many branches of science, bringing greater international visibility to South African science.

Scientists who are research intensive are often collaboration intensive too. An active researcher engaged in a number of research projects is likely to be an active collaborator. ${ }^{49}$ All major sectors - the university, research institutes, industry and government - are part of collaboration. ${ }^{42}$ Sectorally, research institutes favour domestic collaboration whereas universities incline more towards international collaboration. ${ }^{49}$

Traditionally, the productivity of scientists has received encouragement in South Africa which is now being continued through mechanisms such as incentives for publications. Collaborations produce undeniable effects on the productivity of partners. An increase in the number of international collaborative projects is associated with an increase in the publication output of South African scientists. Domestic collaboration does not have as much of an effect on the productivity of scientists as international collaboration does.

Communication, specifically via email and the Internet, is a powerful factor in the collaboration endeavours of South African scientists. ${ }^{41}$ Compared to other modes of communication - postal mail, telephone, fax and face-to-face - email is the most prominent medium for research communication, advancing the collaborative research interests of scientists. ${ }^{41,49}$ Adequate infrastructure, access to modern ICTs, and their effective usage serve scientists in their collaborative research. In contrast to non-collaborative researchers, collaborators maintain diverse and larger networks. In given circumstances, contacts and networks might lead to new collaborative alliances. Collaboration and networks are interrelated ${ }^{41,49}$ : international networks positively affect international collaborations and international projects have larger international networks.

In South Africa, for reasons of common focus and need, and in view of the disappearing scientific skills, there is ample room for pooling together locally and regionally dispersed skills and expertise in science and technology. Affiliated institutions of the new breed of scientists have to provide a functional research environment. Provision of funds for research, travel and conferences without bureaucratic hurdles is not a precondition but should be matched with a human touch for personal encouragement and support. Combined with this personal support and encouragement is an incentive mechanism that takes care of research freedom and autonomy, career advancement, encouragement and adequate remuneration. We have already seen the effect of a similar system in the country.

A major challenge for the country is to retain its researchers and scientists in their professions. For every thousand members in the workforce, South Africa has fewer than one researcher. ${ }^{35}$ The crucial role that scientists and researchers play needs to be known beyond the confining walls of scientific institutions. This makes scientists and researchers feel that the hard work they undertake and the life they live in laboratories and libraries is appreciated by the outside world. A better public image of scientists and researchers will inspire newcomers to join the band and strengthen the scientific system of South Africa.

\section{References}

1. Arvanitis R, Waast R, Gaillard J. Science in Africa: A bibliometric panorama using PASCAL database. Scientometrics. 2000;47(3):457-473. http://dx.doi. org/10.1023/A:1005615816165

2. Zeleza PT. The politics of historical and social science research in Africa. J S Afr Stud. 2002;28(1):9-23. http://dx.doi.org/10.1080/03057070120116953

3. Odhiambo TR. East Africa: Science for development. Science (New Series). 1967;158(3803):876-881. http://dx.doi.org/10.1126/science.158.3803.876
4. Cole S, Phelan TJ. The scientific productivity of nations. Minerva. 1999;37(1):1-23. http://dx.doi.org/10.1023/A:1004591413630

5. Hicks DM, Katz JS. Where is science going? Sci Tec Hum Val. 1996;21 (4):379-406. http://dx.doi.org/10.1177/016224399602100401

6. Bozeman B, Boardman C. Managing the new multipurpose, multidiscipline university research centers: Institutional innovation in the academic community. Washington DC: IBM Center for the Business of Government; 2003.

7. Katz JS, Martin BR. What is research collaboration? Res Pol. 1997;26(1):1-18. http://dx.doi.org/10.1016/S0048-7333(96)00917-1

8. Adams JD, Black GC, Clemmons JR, Stephen PE. Scientific teams and institutional collaborations: Evidence from U.S. universities, 1981-1999. Res Pol. 2005;34(3):259-285. http://dx.doi.org/10.1016/j.respol.2005.01.014

9. Wen J, Kobayashi S. Exploring collaborative R\&D network: Some new evidence in Japan. Res Pol. 2001;30(8):1309-1319. http://dx.doi. org/10.1016/S0048-7333(00)00152-9

10. Bok BJ. Science in international cooperation. Science (New Series). 1955;121(3155):843-847. http://dx.doi.org/10.1126/science.121.3155.843

11. Bozeman B, Boardman C. Research and technology collaboration and linkages: Implications from two U.S. case studies [document on the Internet]. c2003 [cited 2007 Apr 24]. Available from: http://www.csta-cest.ca/files/ usa.pdf

12. Georghiou L. Evolving frameworks for European collaboration in research and technology. Res Pol. 2001;30(6):891-903. http://dx.doi.org/10.1016/ S0048-7333(00)00163-3

13. Hagstrom WO. Traditional and modern forms of scientific teamwork. Adm Sci Qua. 1964;9(3):241-263. http://dx.doi.org/10.2307/2391440

14. Fox MF, Faver CA. Independence and cooperation in research: The motivations and costs of collaboration. J High Educ. 1984;55(3):347-359. http://dx.doi. org/10.2307/1981888

15. Lee YS. Technology transfer and the research university: A search for boundaries of university-industry collaboration. Res Pol. 1996;25(6):843-863. http://dx.doi.org/10.1016/0048-7333(95)00857-8

16. Olson GM, David PA, Eksteen J, Sonnenwald DH, Uhlir PF, Tseng S-F, et al. International collaborations through the Internet. In: Shrum W, Benson K, Bijker W, Brunnstein K, editors. Past, present and future of research in the information society. New York: Springer; 2007. p. 97-114. http://dx.doi. org/10.1007/978-0-387-47650-6_7

17. Sonnenwald $\mathrm{DH}$. Scientific collaboration: A synthesis of challenges and strategies. In: Blaise C, editor. Annual review of information science and technology. NJ: Medford; 2007. p. 643-683.

18. Melin G. Pragmatism and self-organization: Research collaboration on the individual level. Res Pol. 2000;29(1):31-40. http://dx.doi.org/10.1016/ S0048-7333(99)00031-1

19. Peterson BJ. The costs and benefits of collaborative research. Estuaries. 1993;16(4):913-918. http://dx.doi.org/10.2307/1352449

20. Bozeman B, Corley E. Scientists' collaboration strategies: Implications for scientific and technical human capital. Res Pol. 2004;33(4):599-616. http:// dx.doi.org/10.1016/j.respol.2004.01.008

21. Bush V. Professional collaboration. Science. 1957;125(3237):49-54. http:// dx.doi.org/10.1126/science.125.3237.49

22. Bickel WE, Hattrup RA. Teachers and researchers in collaboration: Reflections on the process. Am Educ Res J. 1995;32(1):35-62. http://dx.doi. org/10.3102/00028312032001035

23. John-Steiner V, Weber RJ, Minnis M. The challenge of studying collaboration. Am Educ Res J. 1998;35(4):773-783. http://dx.doi. org/10.3102/00028312035004773

24. Arunachalam S, Doss JJ. Science in a small country at a time of globalization: Domestic and international collaboration in new biology research in Israel. J Inf Sci. 2000;26(1):39-49. http://dx.doi.org/10.1177/016555150002600104

25. Kim KW. Measuring international research collaboration of peripheral countries: Taking the context into consideration. Scientometrics. 2006;66(2):231-240. http://dx.doi.org/10.1007/s11192-006-0017-0

26. CohenJ.Balancingthecollaborationequation.Science.2000;288(5474):21552159. http://dx.doi.org/10.1126/science.288.5474.2155 
27. Hamel G. Competition for competence and inter-partner learning within international strategic alliances. Strategic Manage J. 1991;12:83-103. http:// dx.doi.org/10.1002/smj.4250120908

28. Sonnenwald DH, Pierce L. Information behaviour in dynamic group work contexts: Interwoven situational awareness, dense social networks, and contested collaboration in command and control. Inform Process Manag. 2000;36(3): 461-479. http://dx.doi.org/10.1016/S0306-4573(99)00039-4

29. Walsh JP, Maloney NG. Problems in scientific collaboration: Does email hinder or help? [document on the Internet]. c2003 [cited 2010 Dec 10]. Available from: http://tigger.uic.edu/ jwalsh/

30. Mishkin B. Collaboration and data sharing: Continued. Science (New Series) 1996; 271(5246):130. http://dx.doi.org/10.1126/science.271.5246.130a

31. Smalheiser NR, Perkins GA, Jones S. Guidelines for negotiating scientific collaboration. PLoS Bio. 2005;3(6):e217-e218. http://dx.doi.org/10.1371/ journal.pbio.0030217

32. Keay R. Scientific cooperation in Africa. Afr Affairs. 1976;75(298):86-97.

33. Vaughan CL, Reddy BD, Noakes TD, Moran VC. A commentary on the intellectual health of the nation. S Afr J Sci. 2007;103(1/2):22-26.

34. Kahn M. Internationalization of R\&D: Where does South Africa stand? S Afr J Sci. 2007;103(1):7-12.

35. Department of Science and Technology. South Africa's national research and development strategy [document on the Internet]. c2002 [cited 2007 Aug 31]. Available from: http://www.dst.gov.za/publications/reports.php

36. Habib A, Morrow S. Research, research productivity and the state in South Africa. Transformation. 2006;62:9-29. http://dx.doi.org/10.1353/ trn.2007.0006

37. Letseka M. Government incentivization of partnerships in South Africa: An audit of THRIP and the Innovation Fund. Ind High Educ. 2005;April:161-168. http://dx.doi.org/10.5367/0000000053729798

38. Ellis GFR. Science research policy in South Africa. Pretoria: Royal Society, University of Cape Town; 1994.

39. IDRC. Towards a science and technology policy for a democratic South Africa: Mission report. Johannesburg: The International Development Research Centre; 1993.
40. Kaplan D. South Africa's national research and development strategy: A review. Sci Tec Soc. 2004;9(2):273-294. http://dx.doi.org/10.1177/ 097172180400900204

41. Sooryamoorthy R, Shrum W. Does the Internet promote collaboration and productivity? Evidence from the scientific community in South Africa. J Com-Med Com. 2007;12(2);733-751. http://dx.doi.org/10.1111/j.10836101.2007.00347.x

42. Sooryamoorthy R. Collaboration and publication: How collaborative are scientists in South Africa? Scientometrics. 2009;80(2):419-439. http:// dx.doi.org/10.1007/s11192-008-2074-z

43. Sooryamoorthy R. Do types of collaboration change citation? Collaboration and citation patterns of South African science publications. Scientometrics. 2009;81(1):171-193. http://dx.doi.org/10.1007/s11192-009-2126-z

44. Sooryamoorthy R. Medical research in South Africa: A scientometric analysis of trends, patterns, productivity and partnership. Scientometrics. 2010;84(3):863-885. http://dx.doi.org/10.1007/s11192-010-0169-9

45. Sooryamoorthy R. Science and scientific collaboration: Apartheid and after. Scientometrics. 2010;84(2):373-390. http://dx.doi.org/10.1007/s11192009-0106-y

46. Sooryamoorthy $R$. The internationalization of South African medical research, 1975-2005. S Afr J Sci. 2010;106(7/8):19-25. http://dx.doi.org/10.4102/ sajs.v106i7/8.321

47. Sooryamoorthy $R$ Collaboration in South African engineering research. S Afr $\mathrm{J}$ Ind Eng. 2011;22(2):18-26.

48. Schubert T, Sooryamoorthy R. Can the centre-periphery model explain patterns of international scientific collaboration among threshold and industrialised countries? The case of South Africa and Germany. Scientometrics. 2010;83(1):181-203. http://dx.doi.org/10.1007/s11192009-0074-2

49. Sooryamoorthy R. Publication productivity and collaboration of researchers in South Africa: New empirical evidence. Scientometrics. In press 2013, http://dx.doi.org/10.1007/s11192-013-0990-z

50. Sooryamoorthy R. The visibility of engineering research in South Africa. S Afr $J$ Ind Eng. 2010;21(2):1-12 